\title{
Multiple-linear regression to best-estimate of gravity parameters related to simple geometrical shaped structures
}

\author{
Mohammed TLAS, Jamal ASFAHANI* \\ Atomic Energy Commission, \\ P. O. Box 6091, Damascus, Syria, e-mail: pscientific@aec.org.sy
}

\begin{abstract}
A new interpretative approach is proposed to best-estimate of gravity parameters related to simple geometrical shaped structures such as a semi-infinite vertical cylinder, an infinite horizontal cylinder, and a sphere like structures. The proposed technique is based on the multiple-linear regression oriented towards estimating the model parameters, e.g., the depth from the surface to the center of the buried structure (sphere or infinite horizontal cylinder) or the depth from the surface to the top of the buried object (semi-infinite vertical cylinder), the amplitude coefficient, and the horizontal location from residual gravity anomaly profile. The validity of the proposed approach is firstly demonstrated through testing different synthetic data set corrupted and contaminated by a white Gaussian random noise level. The theoretical synthetic obtained results obviously show that the estimated parameters values, derived by the proposed technique are close to the assumed true parameters values. This approach is applied on five real field residual gravity anomalies taken from Cuba, Sweden, Iran, USA, and Germany, where the efficacy of this new approach is consequently proven. A comparable and acceptable agreement is noticed between the results derived by this proposed approach and those obtained from the real field data information.
\end{abstract}

Key words: Gravity anomaly, sphere-like structure, semi-infinite vertical cylinder-like structure, infinite horizontal cylinder-like structure, multiple-linear regression

\section{Introduction}

The geophysical gravity method is largely used in gas and oil exploration. Most of the geological structures in oil and mineral exploration can be approximated by simple geological structures such as a sphere, a semiinfinite vertical cylinder, an infinite horizontal cylinder, a fault, a sheet, and a dike. Several interpretative techniques have been already developed

\footnotetext{
*corresponding author: e-mail: jasfahani@aec.org.sy
} 
to interpret gravity field anomalies, due to simple geometric models. The main objective of those techniques utilize the mentioned approximations to best-estimate the gravity parameters values, e.g., the depth to the buried body and the amplitude coefficient. The developed methods include, linear optimization-simplex algorithm (Asfahani and Tlas, 2015), neural network modeling (Abedi et al., 2010), differential evolution algorithm (Ekinci et al., 2016), graphical methods (Nettleton, 1962; 1976), ratio methods (Bowin et al., 1986; Abdelrahman et al., 1989), Fourier transform (Odegard and Berg, 1965; Sharma and Geldart, 1968), Euler deconvolution (Thompson, 1982), neural network (Elawadi et al., 2001), Mellin transform (Mohan et al., 1986), least-squares minimization approaches (Gupta, 1983; Lines and Treitel, 1984; Abdelrahman, 1990; Abdelrahman et al., 1991; Abdelrahman and El-Araby, 1993; Abdelrahman and Sharafeldin, 1995a), Werner deconvolution (Hartmann et al., 1971; Jain, 1976).

Werner deconvolution technique is extended by Kilty (1983) to analyze the gravity data using both the residual anomaly and its first and second horizontal derivatives. Ku and Sharp (1983) further refined the method by using iteration for reducing and eliminating the interference field and then applied Marquardt's non-linear least squares method to further refine automatically the first approximation provided by deconvolution. A new automatic technique, called AN-EUL, and based on a combination of the analytic signal and the Euler deconvolution method is introduced by Salem and Ravat (2003) to interpret the magnetic data. Both the location and the approximate geometry of a magnetic source can be deduced by the use of the AN-EUL. Fedi (2007) proposed a method called depth from extreme points (DEXP) to interpret any potential field through describing the theory for the gravity and magnetic fields and their derivatives for any order. The DEXP technique allows the estimation of the source depths, density and structural index from the extreme points of a 3D field scaled according to specific power laws of the altitude. An alternative method is presented by Salem and Smith (2005) to estimate both the depth and model type using the first order local wave number approach, without the need for third order derivatives of the field. A normalization of the first order local wave-number anomalies is achieved in their method, where a generalized equation is constructed to estimate the depth of some 2D magnetic sources regardless of the source structure. 
Silva and Barbosa (2003) derived the analytical estimators for the horizontal and vertical source position in 3D Euler deconvolution as a function of the $x, y$, and $z$ derivatives of the magnetic anomaly within a data window. Barbosa et al. (1999) proposed a new criterion, based on the correlation between the total magnetic field anomaly and the estimates of an unknown base level to determine the structural index, Salem et al. (2008) developed a new method based on derivatives of the tilt angle to interpret the gridded magnetic data, where a simple linear equation, similar to the 3D Euler equation is obtained. Their approach evaluates both the horizontal location and the depth of magnetic bodies, without specifying prior information about the nature of the sources. Fedi et al. (2009) proposed a new method based on a 3D multiridge analysis of potential field. Their method assumes a 3D subset in the harmonic region and analyzes the behavior of the potential field ridges, which are built by joining extreme points of the field computed at different altitudes.

Few techniques only however, have treated the determination of shape of the buried structure. These techniques include, for example, Walsh transform (Shaw and Agarwal, 1990), least-squares methods (Abdelrahman and Sharafeldin, 1995b; Abdelrahman et al., 2001a,b), constrained and penalized nonlinear optimization technique (Tlas et al., 2005). The determination of the depth, shape factor, and amplitude coefficient of the buried structure is generally achieved by those methods from residual gravity anomaly, where the accuracy of the results, gathered by them, depend on the accuracy in which the residual anomaly can be separated and isolated from the observed gravity anomaly.

A simple and easy interpretative approach based on the multiple-linear regression is proposed to interpret residual gravity field anomalies and to best-estimate the model parameters values, e.g., the depth to the top or to the center of the body, the horizontal location and the amplitude coefficient related to a buried sphere or a semi-infinite vertical cylinder or an infinite horizontal cylinder-like structure.

The validity of the new proposed approach is demonstrated using synthetic data set corrupted and contaminated by white Gaussian random noise levels of $15 \%$ and $25 \%$. The theoretical obtained results clearly show that the estimated parameter values derived by this approach are very close to the assumed true values of parameters. 
The accuracy of the new proposed approach is also proven through interpreting five real field gravity anomalies, taken from Cuba, Sweden, Iran, USA, and Germany. The obtained results indicate acceptable and comparable agreements between the results derived by the proposed technique and those obtained by other interpretation methods. The depth obtained by the proposed method is moreover found to be in high accordance with that obtained from the real field data information.

\section{Theory}

A theoretical and synthetic residual gravity anomaly related to various geological models such as a sphere, a semi-infinite vertical cylinder and an infinite horizontal cylinder are treated to demonstrate the validity and the applicability of the new proposed approach.

\subsection{Interpretation of residual gravity anomaly due to simple ge- ometrical models}

The general expression of the residual gravity anomaly $(V)$ at any point $M(x)$ along the $x$-axis of a semi-infinite vertical cylinder-like structure, an infinite horizontal cylinder-like structure and a sphere-like structure, in a Cartesian coordinate system (Fig. 1) can be written according to Gupta (1983), and Asfahani and Tlas (2015) as:

$V\left(x_{i}\right)=\frac{k}{\left(\left(x_{i}-x_{0}\right)^{2}+z^{2}\right)^{q}}, \quad i=1, \ldots, N$,

where $q$ is the geometrical shape factor of the buried structure given in discrete values as follows: $q=1.5$ for a sphere, $q=0.5$ for a semi-infinite vertical cylinder and $q=1$ for an infinite horizontal cylinder, $x_{0}$ is the horizontal location of the buried body, $z$ is the depth from the surface to the center of the buried structure (sphere or infinite horizontal cylinder) or the depth from the surface to the top of the buried object (semi-infinite vertical cylinder), $k$ is the amplitude coefficient given by the following mathematical expression: $k=\frac{4}{3} \pi G \rho r^{3} z$ for a sphere, $k=\pi G \rho r^{2}$ for a semi-infinite vertical cylinder and $k=2 \pi G \rho r^{2} z$ for an infinite horizontal cylinder, $\rho$ is the density contrast, $G$ is the universal gravitational constant, $r$ is the radius, and finally $x_{i}, i=1, \ldots, N$ is the horizontal position coordinate. 


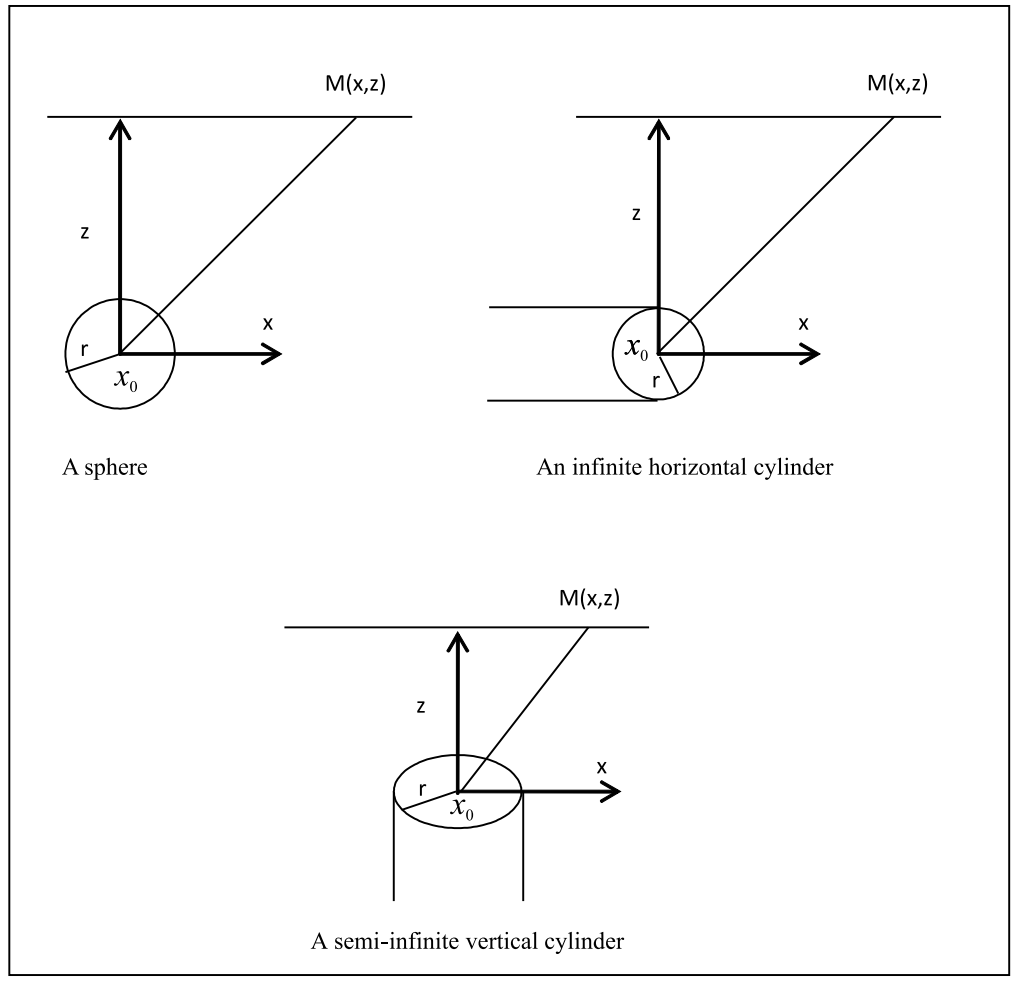

Fig. 1. Diagrams of simple geometrical structures (sphere, infinite horizontal cylinder, and semi-infinite vertical cylinder).

The set of Eq. (1) consists of $N$ nonlinear equations in function of the three independent parameters $k, x_{0}$ and $z$. The term $V_{i}$ will be used, for simplification, instead of the term $V\left(x_{i}\right), i=1, \ldots, N$, in the rest of the paper.

From Eq. (1), it can be easily observed that the sign of the parameter $k$ is similar and coincident to the sign of $V_{i}, i=1, \ldots, N$.

Taking the absolute values of both sides of Eq. (1) we find:

$\left|V_{i}\right|=\frac{|k|}{\left(\left(x_{i}-x_{0}\right)^{2}+z^{2}\right)^{q}}, \quad i=1, \ldots, N$.

After the performing of some mathematical manipulation of the Eq. (2) we get: 
$\left|V_{i}\right|^{\frac{1}{q}} x_{i}^{2}=2 x_{0}\left|V_{i}\right|^{\frac{1}{q}} x_{i}-\left(x_{0}^{2}+z^{2}\right)\left|V_{i}\right|^{\frac{1}{q}}+|k|^{\frac{1}{q}}, \quad i=1, \ldots, N$.

The introduction of the following new variables:

$A=2 x_{0}$,

$B=-\left(x_{0}^{2}+z^{2}\right)$,

$C=|k|^{\frac{1}{q}}$,

$O_{i}=\left|V_{i}\right|^{\frac{1}{q}} x_{i}^{2}, \quad i=1, \ldots, N$,

$P_{i}=\left|V_{i}\right|^{\frac{1}{q}} x_{i}, \quad i=1, \ldots, N$,

$Q_{i}=\left|V_{i}\right|^{\frac{1}{q}}, \quad i=1, \ldots, N$,

into Eq. (3) allows to write the following equation:

$O_{i}=A P_{i}+B Q_{i}+C, \quad i=1, \ldots, N$.

Eq. (8) being linear between the variables $O_{i}, P_{i}, Q_{i}, i=1, \ldots, N$, the unique optimal values of the coefficients $A, B$, and $C$ for a specific discrete value of $q \in\{0.5,1,1.5\}$, a priori assumed, can be easily determined. Such determination is carried out through performing the multiple-linear regression between the dependent variable $O_{i}, i=1, \ldots, N$ and the independent variables $P_{i}, Q_{i}, i=1, \ldots, N$, with the use of one of the familiar statistical programs as Microsoft Excel or Statistica, and or through solving the following set of simultaneously linear equations by the well-known direct method of Gauss:

$$
\begin{aligned}
& \left(\sum_{i=1}^{N} P_{i}^{2}\right) A+\left(\sum_{i=1}^{N} P_{i} Q_{i}\right) B+\left(\sum_{i=1}^{N} P_{i}\right) C=\sum_{i=1}^{N} O_{i} P_{i}, \\
& \left(\sum_{i=1}^{N} P_{i} Q_{i}\right) A+\left(\sum_{i=1}^{N} Q_{i}^{2}\right) B+\left(\sum_{i=1}^{N} Q_{i}\right) C=\sum_{i=1}^{N} O_{i} Q_{i}, \\
& \left(\sum_{i=1}^{N} P_{i}\right) A+\left(\sum_{i=1}^{N} Q_{i}\right) B+(N) C=\sum_{i=1}^{N} O_{i} .
\end{aligned}
$$

The best-estimate of the horizontal location $\left(x_{0}\right)$ of the buried body can be obtained from Eq. (4), after knowing the unique optimal values of $A, B$ and $C$ for $q \in\{0.5,1,1.5\}$ as the following: 
$x_{0}=\frac{A}{2}$.

The best-estimate of the depth $(z)$ from the surface to the center of the buried structure (sphere or infinite horizontal cylinder) or the depth from the surface to the top of the buried object (semi-infinite vertical cylinder) can be derived from Eq. (5) as:

$z=\frac{\sqrt{\left|4 B+A^{2}\right|}}{2}$

The best-estimate of the amplitude coefficient $(k)$ can be also obtained from Eq. (6) as:

$k=C^{q}$ when $V_{i} \geq 0, \quad i=1, \ldots, N$,

$k=-C^{q}$ when $V_{i} \leq 0, \quad i=1, \ldots, N$.

It is useful to mention that there is no loss of generality in assuming the source geometry of the gravity anomaly as a priori known. In addition, there are no imposed restrictions on the generality of the proposed approach.

Before explaining how we can solve this ambiguity and this inconvenience, we will define the statistical criterion of preference called the Root Mean Square Error (RMSE; Collins, 2003). RMSE is based on the minimal value, between the field gravity data anomaly and the computed gravity one, obtained through using the estimated values of $z, x_{0}$ and $k$ resulted from Eqs. (10-13) for a specific discrete value of the geometric shape factor $q \in\{0.5,1,1.5\}$. The mathematical formula of this statistical criterion $R M S E$ is given as:

$R M S E=\sqrt{\frac{\sum_{i=1}^{N}\left(V_{i}(\text { Observed })-V_{i}(\text { Computed })\right)^{2}}{N}}$,

where $V_{i}($ Observed $)$ and $V_{i}$ (Computed $), i=1, \ldots, N$ are the observed and the computed gravity values at the point $x_{i}, i=1, \ldots, N$, respectively.

In the case where the source geometry of the gravity field anomaly is unknown, the following next procedure composed of three steps should be followed: 
- First, the gravity field anomaly is interpreted by adapting and assuming the source geometry as a semi-infinite vertical cylinder $(q=0.5)$, where Root Mean Square Error RMSE_V is computed using Eq. (14) with the estimated values of $z, x_{0}$ and $k$ derived from Eqs. (10-13).

- Second, the gravity field anomaly is re-interpreted by adapting the source geometry as an infinite horizontal cylinder $(q=1)$, where the Square Correlation Coefficient $R M S E_{-} H$ is also computed using Eq. (14) with the estimated values of $z, x_{0}$ and $k$ derived from Eqs. (10-13).

- Third, the gravity field anomaly is re-interpreted by assuming the source geometry as a sphere $(q=1.5)$, where the Square Correlation Coefficient $R M S E \_S$ is also computed using Eq. (14) with the estimated values of $z, x_{0}$ and $k$ derived from Eqs. (10-13).

The lowest one of the three reached values of $R M S E_{-} V, R M S E_{-} H$ and $R M S E \_S$ is selected as a convincible solution, which exactly indicates to the suitable source geometry related to the responsible gravity field anomaly.

Another statistical criterion of preference (square of correlation coefficient) can be also used to select the best optimum gravity solution. It is defined through the following mathematical expression:

$$
R^{2}=\frac{\left(\sum_{i=1}^{N}\left(V_{i}(\text { Obs. })-\bar{V}(\text { Obs. })\right) \times\left(V_{i}(\text { Comp. })-\bar{V}(\text { Comp. })\right)\right)^{2}}{\sum_{i=1}^{N}\left(V_{i}(\text { Obs. })-\bar{V}(\text { Obs. })\right)^{2} \times \sum_{i=1}^{N}\left(V_{i}(\text { Comp. })-\bar{V}(\text { Comp. })\right)^{2}},
$$

where $\bar{V}$ (Obs.) and $\bar{V}$ (Comp.) are the arithmetic means of $V_{i}(O b s$.$) and$ $V_{i}(C o m p$. $), i=1, \ldots, N$ respectively. $R$-squared is computed for the three assumed types of geometric shapes of the buried structure, $R^{2}{ }_{-} V, R^{2}{ }_{-} H$ and $R^{2}{ }_{S} S$ for a semi-infinite vertical cylinder $(q=0.5)$, an infinite horizontal cylinder $(q=1)$, and a sphere $(q=1.5)$ respectively, by using Eq. (15) with the estimated values of $z, x_{0}$ and $k$ resulted from Eqs. (10-13).

The highest one of the three reached values of $R^{2}{ }_{-} V, R^{2}{ }_{-} H$ and $R_{-}^{2} S$ is selected as a convincible solution, which directly indicates to the suitable source geometry related to the responsible gravity field anomaly. 


\subsection{Interpretation of a synthetic gravity anomaly due to a sphere model with Gaussian random noise}

A synthetic gravity anomaly $V\left(x_{i}\right), i=1, \ldots, N$ due to a sphere-like structure is generated from Eq. (1), by using the following values of model parameters: geometric shape factor $q=1.5$, depth from the surface to the center of the buried spherical structure $z=35 \mathrm{~m}$, amplitude coefficient $k=1500 \mathrm{mGal} \mathrm{m}^{3}$, and the horizontal location $x_{0}=5 \mathrm{~m}$.

The generated synthetic anomaly is contaminated by white Gaussian random noise of $15 \%$ and $25 \%$ maximum level using continuous normal distribution, such as new additional gravity anomalies are generated (Fig. 2 and Fig. 3). This regenerated gravity anomalies are consequently interpreted by the new proposed approach. The obtained parameters $\left(z, k, x_{0}\right)$ and the preference criterions $\left(R M S E, R^{2}\right)$ for the three structures a priori assumed; a semi-infinite vertical cylinder, an Infinite horizontal cylinder, and a sphere are summarized in detail in Table 1.

From Table 1, the lowest one of the three reached values of $R M S E_{-} V$, $R M S E_{-} H$ and $R M S E \_S$ or the highest one of the three reached values of $R_{-}^{2} V, R_{-}^{2} H$ and $R_{-}^{2} S$ clearly indicates that the suitable source geometry related to the responsible contaminated synthetic gravity anomaly is a sphere.

The results presented in Table 1 show that the estimated parameter values, obtained by the proposed method, are very close to the true assumed

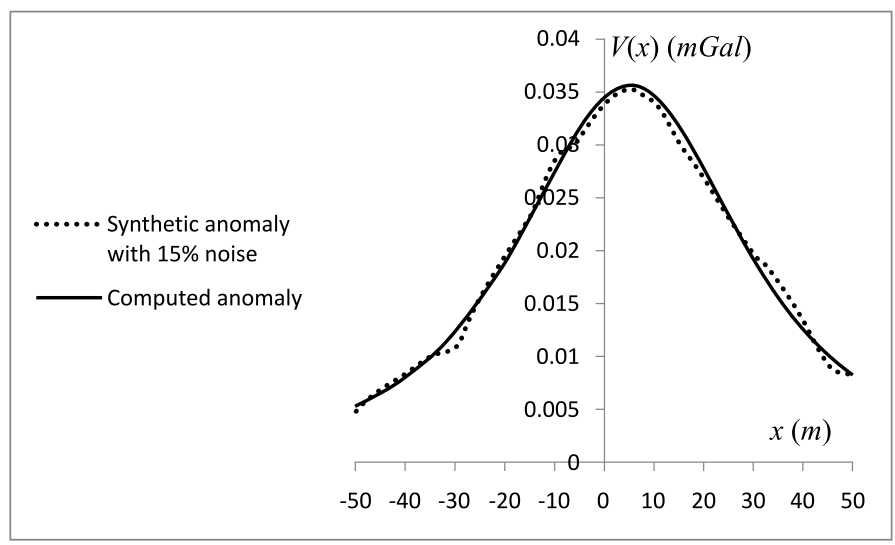

Fig. 2. Diagrams of the computed anomaly and synthetic data set due to a sphere with adding a maximum of $15 \%$ random noise. 


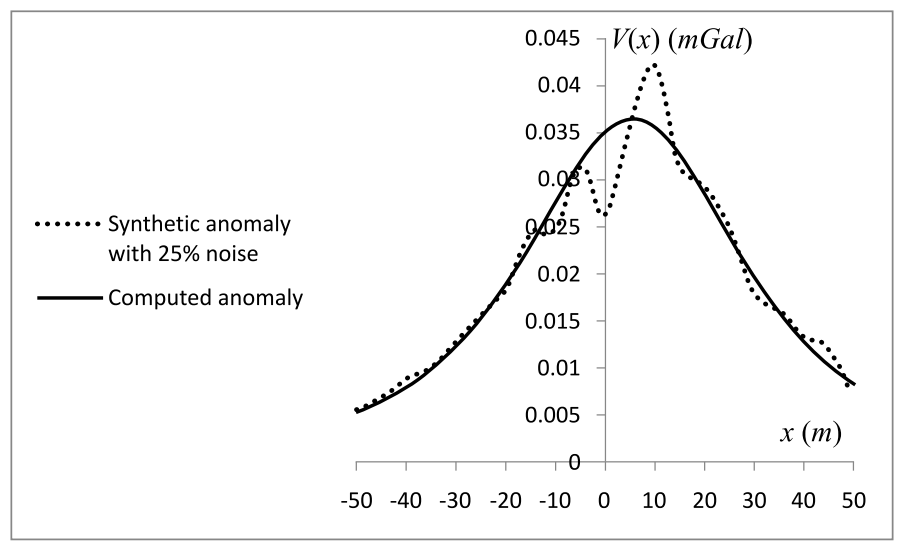

Fig. 3. Diagrams of the computed anomaly and synthetic data set due to a sphere with adding a maximum of $25 \%$ random noise.

Table 1. Interpretation of a synthetic gravity anomaly with $15 \%$ and $25 \%$ maximum level of Gaussian random noise.

\begin{tabular}{|c|c|c|c|c|}
\hline $\begin{array}{l}\text { Source geometric } \\
\text { shape }\end{array}$ & $\begin{array}{l}\text { Model } \\
\text { parameters }\end{array}$ & $\begin{array}{l}\text { True values } \\
\text { of model } \\
\text { parameters }\end{array}$ & $\begin{array}{l}\text { Estimated values } \\
\text { of model param- } \\
\text { eters with max- } \\
\text { imum } 15 \% \text { ran- } \\
\text { dom noise }\end{array}$ & $\begin{array}{l}\text { Estimated values } \\
\text { of model param- } \\
\text { eters with max- } \\
\text { imum } 25 \% \text { ran- } \\
\text { dom noise }\end{array}$ \\
\hline $\begin{array}{l}\text { Semi-infinite } \\
\text { vertical cylinder } \\
\quad(q=0.5)\end{array}$ & $\begin{array}{c}z(\mathrm{~m}) \\
k(\mathrm{mGal} \mathrm{m}) \\
x_{0}(\mathrm{~m}) \\
R M S E(\mathrm{mGal}) \\
R^{2}\end{array}$ & $\begin{array}{c}35 \\
1500 \\
5 \\
- \\
-\end{array}$ & $\begin{array}{l}9.6802 \\
0.4400 \\
5.7053 \\
0.0040 \\
0.9005\end{array}$ & $\begin{array}{l}9.2577 \\
0.4402 \\
6.0398 \\
0.0045 \\
0.8659\end{array}$ \\
\hline $\begin{array}{l}\text { Infinite hori- } \\
\text { zontal cylinder } \\
\qquad(q=1)\end{array}$ & $\begin{array}{c}z(\mathrm{~m}) \\
k\left(\mathrm{mGal} \mathrm{m}^{2}\right) \\
x_{0}(\mathrm{~m}) \\
R M S E(\mathrm{mGal}) \\
R^{2}\end{array}$ & $\begin{array}{c}35 \\
1500 \\
5 \\
- \\
-\end{array}$ & $\begin{array}{c}24.1526 \\
21.9485 \\
5.5931 \\
0.0025 \\
0.9710\end{array}$ & $\begin{array}{c}23.6664 \\
21.6798 \\
5.8338 \\
0.0028 \\
0.9314\end{array}$ \\
\hline $\begin{array}{l}\text { Sphere } \\
(q=1.5)\end{array}$ & $\begin{array}{c}z(\mathrm{~m}) \\
k\left(\mathrm{mGal} \mathrm{m}^{3}\right) \\
x_{0}(\mathrm{~m}) \\
R M S E(\mathrm{mGal}) \\
R^{2}\end{array}$ & $\begin{array}{c}35 \\
1500 \\
5 \\
- \\
-\end{array}$ & $\begin{array}{l}34.8422 \\
1505 \\
5.5 .2868 \\
0.0019 \\
0.9753\end{array}$ & $\begin{array}{c}34.3145 \\
1472 \\
5.4353 \\
0.0027 \\
0.9342\end{array}$ \\
\hline
\end{tabular}


values of parameters. This clearly proves the efficiency of the new proposed approach.

\section{Application to field data}

The new proposed approach is applied to interpret five field residual gravity anomalies measured over various geological structures. The five field gravity anomalies are interpreted according to the three different geological structures, e.g., a sphere, an infinite horizontal cylinder, and a semi-infinite vertical cylinder. The resulting model with the lowest reached value of $R M S E$ and the highest reached value of $R^{2}$ is selected as the best and the suitable model solution for estimating the parameters of the field residual gravity anomaly.

\subsection{Interpretation of the Chromites filed residual gravity anomaly}

Fig. 4 shows a normalized residual field gravity anomaly measured over a chromites deposit in Camaguey province, Cuba (Robinson and Coruh, 1988). The gravity anomaly is interpreted by the new proposed approach by assuming a priori the source geometry as a semi-infinite vertical cylinder,

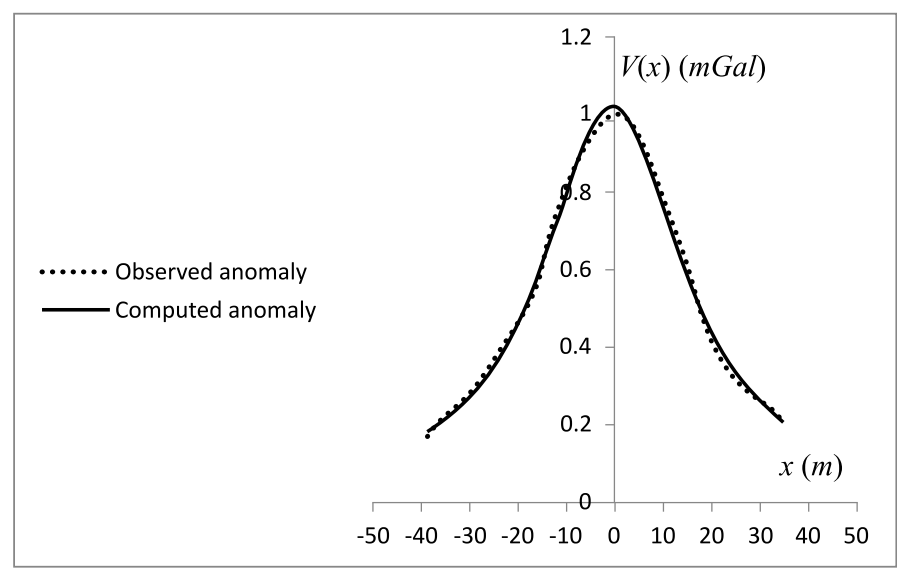

Fig. 4. Normalized residual gravity field anomaly over a chromites deposit, Camaguey province, Cuba. The evaluated curve by the proposed approach is presented for an infinite horizontal cylinder model. 
an infinite horizontal cylinder, and a sphere. All acquired results are shown in Table 2.

Table 2. Interpretation of the Chromites field residual gravity anomaly, Cuba.

\begin{tabular}{cccc}
\hline $\begin{array}{l}\text { Model } \\
\text { parameters }\end{array}$ & $\begin{array}{l}\text { Semi-infinite } \\
\text { vertical cylinder }\end{array}$ & $\begin{array}{l}\text { Infinite horizontal } \\
\text { cylinder }\end{array}$ & Sphere \\
\hline$z(\mathrm{~m})$ & 7.2116 & 17.7302 & 25.5077 \\
$k$ & $8.6920(\mathrm{mGal} \mathrm{m})$ & $321.3769\left(\mathrm{mGal} \mathrm{m}^{2}\right)$ & $16121\left(\mathrm{mGal} \mathrm{m}^{3}\right)$ \\
$x_{0}(\mathrm{~m})$ & -0.6609 & -0.5827 & -0.6541 \\
$R M S E(\mathrm{mGal})$ & 0.0742 & 0.0153 & 0.0219 \\
$R^{2}$ & 0.9443 & 0.9971 & 0.9944 \\
\hline
\end{tabular}

The lowest one of the three reached values of $R M S E_{-} V, R M S E_{-} H$ and $R M S E_{-} S$ with the highest one of the three reached values of $R^{2}{ }_{-} V, R^{2}{ }_{-} H$ and $R_{-}^{2} S$ are obtained for the infinite horizontal cylinder, meaning that, the field residual gravity anomaly could be preferably modeled as an infinite horizontal cylinder. The depth obtained in this case $(z=17.7302 \mathrm{~m})$ is found to be in a good agreement with that obtained from drill-hole information $(z=21 \mathrm{~m})$ (Robinson and Coruh, 1988). The computed gravity anomaly is drawn according to the estimated values of infinite horizontal cylinder model parameters as shown in Fig. 4. The comparison between field and computed anomalies shows a close agreement between them, which certainly attests the validity of the new proposed approach.

\subsection{Interpretation of the Karrbo field residual gravity anomaly}

Fig. 5 shows a field residual gravity anomaly of a profile $25.6 \mathrm{~m}$ length obtained over the two-dimensional pyrrhotite ore, Karrbo, Vastmanland, Sweden (Shaw and Agarwal, 1990). The field gravity anomaly is also interpreted by the proposed approach for the three different structures a priori assumed, where the gathered results are summarized in Table 3.

The lowest one of the three reached values of $R M S E_{-} V, R M S E_{-} H$ and $R M S E_{-} S$ with the highest one of the three reached values of $R^{2}{ }_{-} V, R_{-}^{2} H$ and $R_{-}^{2} S$ are obtained for the infinite horizontal cylinder, meaning that, the field residual gravity anomaly could be preferably modeled as an infinite horizontal cylinder. The depth obtained in this case $(z=4.7062 \mathrm{~m})$ is found to be in good agreement with the depth reported by Tlas et al. (2005) 


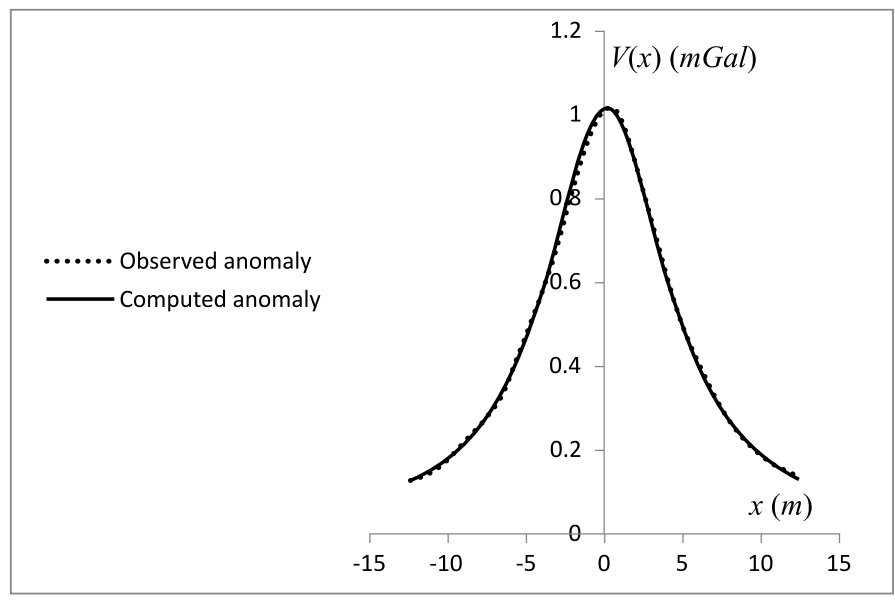

Fig. 5. Residual gravity field anomaly over the two-dimensional pyrrhotite ore, Karrbo, Vastmanland, Sweden. The evaluated curve by the proposed method is presented for an infinite horizontal cylinder model.

Table 3. Interpretation of the Karrbo field residual gravity anomaly, Sweden.

\begin{tabular}{cccc}
\hline $\begin{array}{l}\text { Model } \\
\text { parameters }\end{array}$ & $\begin{array}{l}\text { Semi-infinite } \\
\text { vertical cylinder }\end{array}$ & $\begin{array}{l}\text { Infinite horizontal } \\
\text { cylinder }\end{array}$ & Sphere \\
\hline$z(\mathrm{~m})$ & 1.5839 & 4.7062 & 7.057 \\
$k$ & $2.1303(\mathrm{mGalm})$ & $22.5104\left(\mathrm{mGal} \mathrm{m}^{2}\right)$ & $331.0846\left(\mathrm{mGal} \mathrm{m}^{3}\right)$ \\
$x_{0}(\mathrm{~m})$ & 0.1693 & 0.1772 & 0.1767 \\
$R M S E(\mathrm{mGal})$ & 0.0947 & 0.0055 & 0.0279 \\
$R^{2}$ & 0.9252 & 0.9996 & 0.9922 \\
\hline
\end{tabular}

$(z=4.82 \mathrm{~m})$, Asfahani and Tlas (2015) $(z=4.7 \mathrm{~m})$, Shaw and Agarwal (1990) $(z=5.8 \mathrm{~m})$, and El-Araby (2000) ( $z=5.23 \mathrm{~m})$. The computed gravity anomaly is drawn according to the estimated values of infinite horizontal cylinder model parameters as shown in Fig. 5. The comparison between field and computed anomalies shows a close agreement between them, which attests the capability and the validity of the new suggested approach.

\subsection{Interpretation of the Dehloran field residual gravity anomaly}

Fig. 6 shows a field residual gravity anomaly obtained over an area located in West of Iran in the Zagros tectonic zone, Iran (Abedi et al., 2010). The 


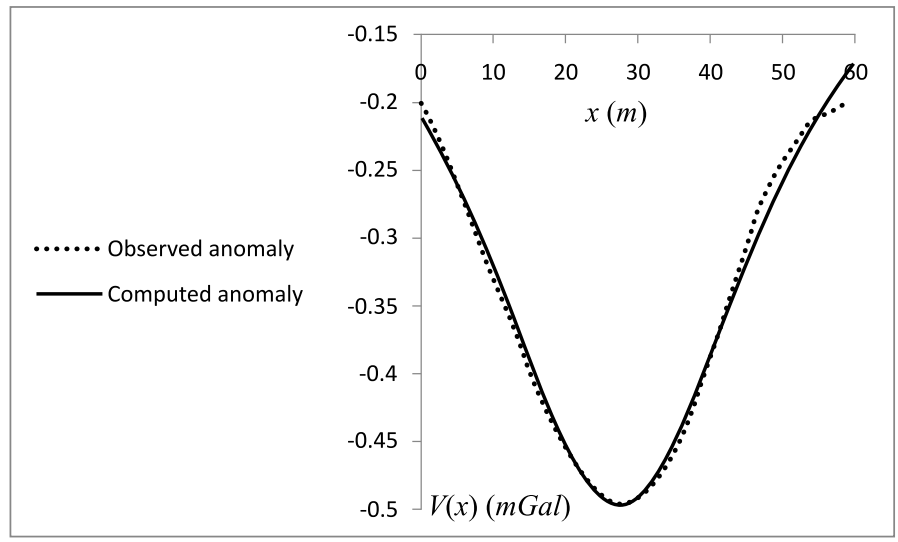

Fig. 6. Residual gravity field anomaly over an area located in West of Iran in the Zagros tectonic zone, Iran. The evaluated curve by the proposed method is presented for an infinite horizontal cylinder model.

field gravity anomaly is interpreted by the proposed approach, where the interpretative results are presented in Table 4.

Table 4. Interpretation of the Dehloran field residual gravity anomaly, Iran.

\begin{tabular}{cccc}
\hline $\begin{array}{l}\text { Model } \\
\text { parameters }\end{array}$ & $\begin{array}{l}\text { Semi-infinite } \\
\text { vertical cylinder }\end{array}$ & $\begin{array}{l}\text { Infinite horizontal } \\
\text { cylinder }\end{array}$ & Sphere \\
\hline$z(\mathrm{~m})$ & 12.7586 & 23.6345 & 31.4088 \\
$k$ & $-6.657(\mathrm{mGal} \mathrm{m})$ & $-277.2779\left(\mathrm{mGal} \mathrm{m}^{2}\right)$ & $-15142\left(\mathrm{mGal} \mathrm{m}^{3}\right)$ \\
$x_{0}(\mathrm{~m})$ & 27.1784 & 27.4276 & 27.5829 \\
$R M S E(\mathrm{mGal})$ & 0.0147 & 0.0097 & 0.0122 \\
$R^{2}$ & 0.9814 & 0.9915 & 0.9865 \\
\hline
\end{tabular}

The lowest one of the three reached values of $R M S E \_V, R M S E_{-} H$ and $R M S E_{-} S$ with the highest one of the three reached values of $R^{2}{ }_{-} V, R^{2}{ }_{-} H$ and $R_{-}^{2} S$ are obtained for the infinite horizontal cylinder, meaning that, the field residual gravity anomaly could be preferably modeled as an infinite horizontal cylinder. The depth obtained in this case $(z=23.6345 \mathrm{~m})$ is found to be in good agreement with that reported by (Abedi et al., 2010), by using three different interpretation methods, the normalized method $(z=23.73 \mathrm{~m})$, the least-squares method $(z=23.3145 \mathrm{~m})$, the neural network method $(z=22.8 \mathrm{~m})$, and also with that obtained from drill-hole information $(z=23 \mathrm{~m})$ (Abedi et al., 2010). 
The computed gravity anomaly is drawn according to the estimated values of infinite horizontal cylinder model parameters as shown in Fig. 6. The comparison between field and computed anomalies shows a close agreement between them, which attests the validity of the suggested approach.

\subsection{Interpretation of the Humble field residual gravity anomaly}

Fig. 7 shows a field residual gravity anomaly obtained over an area located near the town of Humble in north-eastern Harris County on the Upper Gulf Coast of Texas, USA (Nettleton, 1962; Abdelrahman and Gobashy, 2017). The field gravity anomaly is newly reinterpreted by the proposed approach. The results related to this residual gravity anomaly are shown in Table 5 .

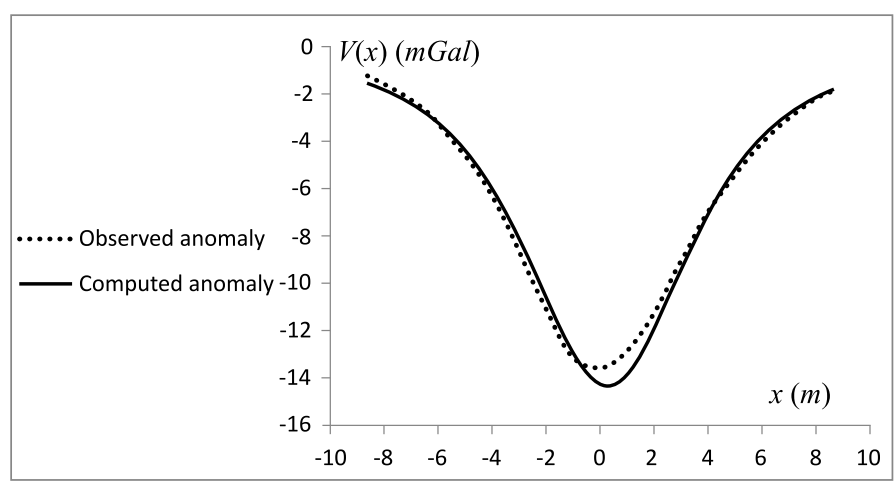

Fig. 7. Residual gravity field anomaly over an area located near the town of Humble in north-eastern Harris County on the Upper Gulf Coast of Texas, USA. The evaluated curve by the proposed method is presented for a sphere model.

Table 5. Interpretation of the Humble field residual gravity anomaly, USA.

\begin{tabular}{cccc}
\hline $\begin{array}{l}\text { Model } \\
\text { parameters }\end{array}$ & $\begin{array}{l}\text { Semi-infinite } \\
\text { vertical cylinder }\end{array}$ & $\begin{array}{l}\text { Infinite horizontal } \\
\text { cylinder }\end{array}$ & Sphere \\
\hline$z(\mathrm{~km})$ & 1.0435 & 3.2087 & 4.8192 \\
$k$ & $-22.4903(\mathrm{mGal} \mathrm{km})$ & $-159.5463\left(\mathrm{mGal} \mathrm{km}^{2}\right)$ & $-1600.2\left(\mathrm{mGal} \mathrm{km}^{3}\right)$ \\
$x_{0}(\mathrm{~km})$ & 0.1423 & 0.2517 & 0.2941 \\
$R M S E(\mathrm{mGal})$ & 2.3061 & 0.7804 & 0.4319 \\
$R^{2}$ & 0.8329 & 0.9744 & 0.9908 \\
\hline
\end{tabular}

The lowest one of the three reached values of $R M S E \_V, R M S E \_H$ and $R M S E \_S$ with the highest one of the three reached values of $R^{2}{ }_{-} V, R_{-}^{2} H$ 
and $R_{-}^{2} S$ has been obtained for the sphere, meaning that, the field residual gravity anomaly could be preferably modeled as a sphere. The depth obtained in this case $(z=4.8192 \mathrm{~km})$ is found to be in a good agreement with that reported by Nettleton (1962) and by Abdelrahman and Gobashy (2017) $(z=5.05 \mathrm{~km})$ using a statistical approach.

The computed gravity anomaly is drawn according to the estimated values of sphere model parameters as shown in Fig. 7. The comparison between field and computed anomalies shows a close agreement between them, which proves the validity of the proposed approach.

\subsection{Interpretation of the Wathlingen field residual gravity anomaly}

Fig. 8 shows a field residual gravity anomaly obtained over an area situated in the southern part of the North-West German Basin, Germany (Dubey et al., 2014; Abdelrahman and Gobashy, 2017). The field gravity anomaly is reinterpreted by the new proposed approach, where the results are shown in Table 6.

The lowest one of the three reached values of $R M S E \_V, R M S E_{-} H$ and $R M S E_{-} S$ with the highest one of the three reached values of $R^{2}{ }_{-} V, R^{2}{ }_{-} H$ and $R_{-}^{2} S$ are obtained for the semi-infinite vertical cylinder, meaning that,

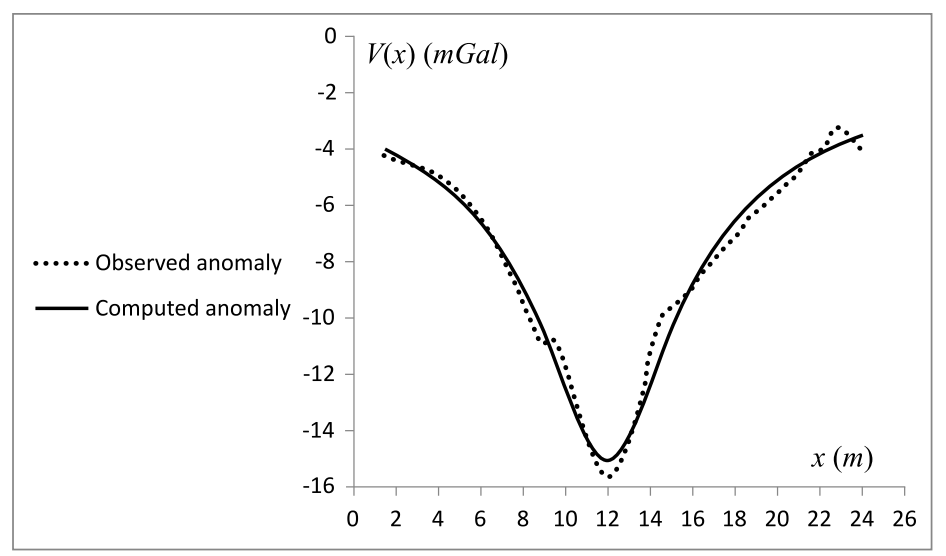

Fig. 8. Residual gravity field anomaly over an area situated in the southern part of the North-West German Basin, Germany. The evaluated curve by the proposed method is presented for a semi-infinite vertical cylinder model. 
Table 6. Interpretation of the Wathlingen field residual gravity anomaly, Germany.

\begin{tabular}{cccc}
\hline $\begin{array}{l}\text { Model } \\
\text { parameters }\end{array}$ & $\begin{array}{l}\text { Semi-infinite } \\
\text { vertical cylinder }\end{array}$ & $\begin{array}{l}\text { Infinite horizontal } \\
\text { cylinder }\end{array}$ & Sphere \\
\hline$z(\mathrm{~km})$ & 2.9155 & 6.2657 & 8.7195 \\
$k$ & $-43.8499(\mathrm{mGal} \mathrm{km})$ & $-541.4824\left(\mathrm{mGal} \mathrm{km}^{2}\right)$ & $-8885.5\left(\mathrm{mGal} \mathrm{km}^{3}\right)$ \\
$x_{0}(\mathrm{~km})$ & 11.9780 & 12.1696 & 12.2627 \\
$R M S E(\mathrm{mGal})$ & 0.5183 & 0.9208 & 1.0871 \\
$R^{2}$ & 0.9828 & 0.9448 & 0.9228 \\
\hline
\end{tabular}

the field residual gravity anomaly could be preferably modeled as a semiinfinite vertical cylinder. The depth obtained in this case $(z=2.9155 \mathrm{~km})$ is found to be in a good agreement with that reported by Dubey et al. (2014) and by Abdelrahman and Gobashy (2017) by using a statistical approach $(z=3.2 \mathrm{~km})$.

The computed gravity anomaly is drawn according to the estimated values of semi-infinite vertical cylinder model parameters as shown in Fig. 8. The comparison between field and computed anomalies shows a close agreement between them, which proves the validity of the proposed approach.

\section{Pseudo-code of the proposed interpretation method}

A pseudo-code of the proposed method is explained and illustrated in this section for interpreting residual gravity anomalies related to three different types of structures, e.g., a semi-infinite vertical cylinder, an infinite horizontal cylinder, and a sphere. Such pseudo-code procedure facilitates and aids to put the interpretation method into a computer code.

The statistical criteria of preference Root Mean Square Error $(R M S E)$ defined in Eq. (14) and the square of correlation coefficient $\left(R^{2}\right)$ defined in Eq. (15) are used in the proposed method in order to choose the suitable source geometry related to the responsible gravity field anomaly.

\section{The pseudo-code procedure}

$V_{i}$ (Observed $), i=1, \ldots, N$ is the observed data, $q$ is the shape factor of the buried structure, $R M S E$ is the root mean square error, $R^{2}$ is the square of correlation coefficient.

\section{begin}

for $q=0.5,1,1.5$ do 
Find the pair values of $R M S E_{-} V$, and $R^{2} \_V$ for a semi-infinite vertical cylinder model $(q=0.5)$

Find the pair values of $\left(R M S E_{-} H, R^{2} \_H\right)$ for an infinite horizontal cylinder $(q=1)$

Find the pair values of $\left(R M S E_{-} V, R_{-}^{2} V\right)$ for a sphere $(q=1.5)$

\section{end for}

Find the parameters $R M S E=\min \left\{R M S E \_V, R M S E \_H, R M S E \_S\right\}$, and $R^{2}=\max \left\{R_{-}^{2} V, R_{-}^{2} H, R_{-}^{2} S\right\}$

if $R M S E=R M S E_{-} V$ or $R^{2}=R_{-}^{2} V$, then

the gravity anomaly could be modeled as a semi-infinite vertical cylinder, end the procedure

else

the gravity anomaly is not preferably to be modeled as a semi-infinite vertical cylinder, continue

\section{end if}

if $R M S E=R M S E \_H$ or $R^{2}=R_{-}^{2} H$, then

the gravity anomaly could be modeled as an infinite horizontal cylinder,

end the procedure

else

the gravity anomaly is not preferably to be modeled as a an infinite

horizontal cylinder, continue

\section{end if}

if $R M S E=R M S E \_S$ or $R^{2}=R^{2} \_S$, then

the gravity anomaly could be modeled as a sphere, end the procedure else

the gravity anomaly is not preferably to be modeled as a sphere end if

end begin

end the pseudo-code

\section{Conclusion}

The new proposed approach is applied to interpret five real field gravity anomalies from Cuba, Sweden, Iran, USA and Germany, where satisfactory results were obtained. 
An acceptable agreement between the results derived by this approach and those obtained by other interpretative methods is shown, which manifests the validity of the proposed approach.

Moreover, the depth obtained by such the new proposed approach is found to be in an acceptable accordance with that obtained by the real field data information.

The new proposed approach could be easily put in MATLAB code or in Excel sheet. It is recommended to apply this method for routine analysis of gravity anomalies for determining the best-estimate values of parameters related to spheres, semi-infinite vertical cylinder and infinite horizontal cylinder-like structures.

Acknowledgements. Authors would like to thank Dr. I. Othman Director General of the Syrian Atomic Energy Commission for his continuous encouragement and guidance to achieve this research. The anonymous reviewers are cordially thanked for their critics, remarks and suggestions that considerably improved the final version of this paper. Dr. Igor Kohut, editor of Contribution to Geophysics and Geodesy Journal is also thanked for his collaboration with the authors during the different stages of publishing this paper.

\section{References}

Abdelrahman E. M., Bayoumi A. I., Abdelhady Y. E., Gobash M. M., El-Araby H. M., 1989: Gravity interpretation using correlation factors between successive leastsquares residual anomalies. Geophysics, 54, 12, 1614-1621, doi: 10.1190/1.1442 629.

Abdelrahman E. M., 1990: On "A least-squares approach to depth determination from gravity data" by Gupta O. P. (Geophysics, 48, 357-360, March 1983), discussion. Geophysics, 55, 3, 376-377, doi: 10.1190/1.1442846.

Abdelrahman E. M., Bayoumi A. I., El-Araby H. M., 1991: A least-squares minimization approach to invert gravity data. Geophysics, 56, 1, 115-118, doi: 10.1190/1.144 2946.

Abdelrahman E. M., El-Araby T. M., 1993: A least-squares minimization approach to depth determination from moving average residual gravity anomalies. Geophysics, 58, 12, 1779-1784, doi: 10.1190/1.1443392.

Abdelrahman E. M., Sharafeldin S. M., 1995a: A least-squares minimization approach to depth determination from numerical horizontal gravity gradients. Geophysics, 60, 4, 1259-1260, doi: 10.1190/1.1443857. 
Abdelrahman E. M., Sharafeldin S. M., 1995b: A least-squares minimization approach to shape determination from gravity data. Geophysics, 60, 2, 589-590, doi : 10.1190/ 1.1443797.

Abdelrahman E. M., El-Araby T. M., El-Araby H. M., Abo-Ezz E. R., 2001a: Three leastsquares minimization approaches to depth, shape, and amplitude coefficient determination from gravity data. Geophysics, 66, 4, 1105-1109, doi: 10.1190/1.1487058.

Abdelrahman E. M., El-Araby T. M., El-Araby H. M., Abo-Ezz E. R., 2001b: A new method for shape and depth determinations from gravity data. Geophysics, 66, 6, 1774-1780, doi: 10.1190/1.1487119.

Abdelrahman E. S., Gobashy M., 2017: Depth and shape solutions from residual gravity anomalies due to simple geometric structures using a statistical approach. Contrib. Geophys. Geod., 47, 2, 113-132, doi : 10.1515/congeo-2017-0008.

Abedi M., Afshar A., Ardestani V. E., Norouzi G. H., Lucas C., 2010: Application of various methods for $2 \mathrm{D}$ inverse modeling of residual gravity anomalies. Acta Geophys., 58, 2, 317-336, doi: 10.2478/s11600-009-0053-2.

Asfahani J., Tlas M., 2015: Estimation of gravity parameters related to simple geometrical structures by developing an approach based on deconvolution and linear optimaization techniques. Pure Appl. Geophys., 172, 10, 2891-2899, doi : 10.1007/s00024-0 15-1068-z.

Barbosa V. C. F., Silva J. B. C., Medeiros W. E., 1999: Stability analysis and improvement of structural index estimation in Euler deconvolution. Geophysics, 64, 1, 48-60, doi: 10.1190/1.1444529.

Bowin C., Scheer E., Smith W., 1986: Depth estimates from ratios of gravity, geoid and gravity gradient anomalies. Geophysics, 51, 1, 123-136, doi: 10.1190/1.1442025.

Collins G. W., 2003: Fundamental numerical methods and data analysis. Case Western Reserve University.

Dubey C. P., Götze H.-J., Schmidt S., Tiwari V. M., 2014: A 3D model of the Wathlingen salt dome in the Northwest Germany Basin from joint modeling of gravity, gravity gradient, and curvature. Interpretation, 2, 4, SJ103-SJ115, doi : 10.1190/INT-2014 $-0012.1$.

Ekinci Y. L., Balkaya Ç., Göktürkler G., Turan S., 2016: Model parameter estimations from residual gravity anomalies due to simple-shaped sources using Differential Evolution Algorithm. Journal of Applied Geophysics, 129, 133-147, doi : j · jappgeo. 20 16.03.040.

El-Araby H. M., 2000: An iterative least-squares minimization approach to depth determination from gravity anomalies. Bull. Fac. Sci., Cairo Univ., 68, 233-243.

Elawadi E., Salem A., Ushijima K., 2001: Detection of cavities from gravity data using a neural network. Explor. Geophys., 32, 3-4, 75-79, doi: 10.1071/EG01204.

Fedi M., 2007: DEXP: A fast method to determine the depth and the structural index of potential fields sources. Geophysics, 72, 1, I1-I11, doi: 10.1190/1.2399452.

Fedi M., Florio G., Quarta T. A. M., 2009: Multiridge analysis of potential fields: Geometric method and reduced Euler deconvolution. Geophysics, 74, 4, L53-L65, doi: $10.1190 / 1.3142722$. 
Gupta O. P., 1983: A least-squares approach to depth determination from gravity data. Geophysics, 48, 3, 357-360, doi: 10.1190/1.1441473.

Hartmann R. R., Teskey D., Friedberg I., 1971: A system for rapid digital aeromagnetic interpretation. Geophysics, 36, 5, 891-918, doi: 10.1190/1.1440223.

Jain S., 1976: An automatic method of direct interpretation of magnetic profiles. Geophysics, 41, 3, 531-541, doi : 10.1190/1.1440631.

Kilty T. K., 1983: Werner deconvolution of profile potential field data. Geophysics, 48, 2, 234-237, doi: 10.1190/1.1441463.

Ku C. C., Sharp J. A., 1983: Werner deconvolution for automatic magnetic interpretation and its refinement using Marquardt's inverse modeling. Geophysics, 48, 6, 754-774, doi: 10.1190/1.1441505.

Lines L. R., Treitel S., 1984: A review of least-squares inversion and its application to geophysical problems. Geophys. Prospect., 32, 2, 159-186, doi: 10.1111/j.1365-2478 .1984.tb00726.x.

Mohan N. L., Anandababu L., Roa S. V., 1986: Gravity interpretation using the Melin transform. Geophysics, 51, 1, 114-122, doi : 10.1190/1.1442024.

Nettleton L. L., 1962: Gravity and magnetics for geologists and seismologists. AAPG Bull., 46, 10, 1815-1838, doi : 10.1306/BC7438F3-16BE-11D7-8645000102C1865D.

Nettleton L. L., 1976: Gravity and magnetics in oil prospecting. Mc-Grow Hill Book Co., $464 \mathrm{p}$.

Odegard M. E., Berg J. W., 1965: Gravity interpretation using the Fourier integral. Geophysics, 30, 3, 424-438, doi: 10.1190/1.1439598.

Robinson E. S., Coruh C., 1988: Basic exploration geophysics. Wiley, New York, NY, $576 \mathrm{p}$.

Salem A., Ravat D., 2003: A combined analytic signal and Euler method (AN-EUL) for automatic interpretation of magnetic data. Geophysics, 68, 6, 1952-1961, doi: $10.1190 / 1.1635049$.

Salem A., Smith R., 2005: Depth and structural index from normalized local wavenumber of 2D magnetic anomalies. Geophys. Prospect., 53, 1, 83-89, doi: 10.1190/1.163 5049 .

Salem A., Williams S., Fairhead D., Smith R., Ravat D., 2008: Interpretation of magnetic data using tilt angle derivatives. Geophysics, 73, 1, L1-L10, doi: 10.1190/1.279 9992.

Sharma B., Geldart L. P., 1968: Analysis of gravity anomalies of two-dimensional faults using Fourier transforms. Geophysical Prospecting, 16, 1, 77-93, doi: 10.1111/j . 1365-2478.1968.tb01961.x.

Shaw R. K., Agarwal B. N. P., 1990: The application of Walsh transform to interpret gravity anomalies due to some simple geometrically shaped causative sources: A feasibility study. Geophysics, 55, 7, 843-850, doi: 10.1190/1.1442898.

Silva J. B. C., Barbosa V. C. F., 2003: 3D Euler deconvolution: Theoretical basis for automatically selecting good solution. Geophysics, 68, 6, 1962-1968, doi: 10.1190/1.16 35050 . 
Thompson D. T., 1982: EULDPH-a new technique for making computer-assisted depth estimates from magnetic data. Geophysics, 47, 1, 31-37, doi: 10.1190/1.1441278.

Tlas M., Asfahani J., Karmeh H., 2005: A versatile nonlinear inversion to interpret gravity anomaly caused by a simple geometrical structure. Pure Appl. Geophys., 162, 12, 2557-2571, doi : 10.1007/s00024-005-2775-7. 